\title{
Research on Social Assistance Urban- Rural Overall Planning
}

\author{
Haixia REN \\ School of Finance, Central University of Finance and Economics Beijing 100081, China \\ School of Finance and Tax, Inner Mongolia University of Finance and Economics, Inner Mongolia, Hohhot \\ 010051,China
}

\begin{abstract}
Social assistance system as a minimum level of social security system, has a profound impact on the whole social security system and social development. This paper analyzes the current situation of dual social assistance system, illustrates the sense of social assistance system urban- rural overall planning, including: achieve social justice, urban and rural development, social stability and harmony. At last, the author propose recommendations in several ways, including: regulatory agencies, funds, non-governmental organizations.
\end{abstract}

KEYWORD: Social Assistance; Urban-Rural Overall Planning; Social Justice

Due to the long-term impact of separation of urban and rural, China's social assistance system was always divided between city and countryside. But with the development of economics and society, the traditional social assistant system has been unable to meet the needs of the people because it has many problems. It is necessary to find the new suitable social assistance system for modern economy and social development.

\section{THE URBAN-RURAL DICHOTOMY OF CHINESE CURRENT SOCIAL ASSISTANT}

\subsection{1 The urban-rural dichotomy of the urban and rural minimum living security system}

Firstly, setup time is not uniform. Urban minimum living security system was first started in Shanghai, which marked the begin of China's reform of social assistance system. September 2, 1997, "The State Council on the Country to Establish Urban Minimum Living Security System notification" issued (No 29 Document in 1997 of the State Council), which proposed all cities and towns should established the urban minimum living security system. To the end of September 1999, 667 cities and 1638 towns nationwide established this system. September 28, 1999, the State Council promulgated the "Regulations minimum living allowance for urban residents", marking this system on a legal track. The system assistants such members: a family member living with per capital income below the local minimum living standard for urban residents.

October 2006, the Sixth Plenary Session of the Sixteenth CPC Central Committee first proposed the gradual establishment of rural minimum living security system in all the countryside. July 11, the State Council issued "on The Establishment of The National Rural Minimum Living Security System Notification" (No 19 Document in 2007 of the State Council), which formulated the content of the rural minimum standard, relief object, standardized management, and other funds to implement. So far, the rural minimum implementation has entered a new stage. To the end of September 2007, 31 provinces have established the rural minimum living security system.

The values of the urban-rural dichotomy of urban and rural resulted a ten years interval between urban and rural minimum living security system.

Now, the minimum living security system uses two institutions, two methods, two standards between rural and urban, which put a lot of migrant workers excluded from the coverage of the system. They are difficult to enjoy the minimum living guarantee relief like urban residents.

Secondly, a large gap in standard between Urban and rural minimum living security system. 
Table 1 Urban and rural low standard

Unit: yuan / month / person

\begin{tabular}{|l|l|l|l|l|l|l|l|}
\hline & 2007 & 2008 & 2009 & 2010 & 2011 & 2012 & 2013 \\
\hline city & 182.4 & 205.3 & 227.75 & 251.2 & 287.6 & 330.1 & 373 \\
\hline $\begin{array}{l}\text { country } \\
\text { side }\end{array}$ & 70 & 82.3 & 100.84 & 117.0 & 143.2 & 172.32 & 202.83 \\
\hline
\end{tabular}

Source: China Statistical Yearbook Social Assistance

From table 1,we can find that in recent years, urban and rural minimum living security system are constantly improving, urban and rural low standard has gradually increased, but the level of assistance in rural areas is still lower than the city.

\subsection{The urban-rural dichotomy of the urban and rural medical assistance}

Firstly, on the medicaid resource allocation, there is a significant difference between urban and rural areas. The contrast of crowded hospitals in large city, the deserted primary hospital in rural is rare. All these formulate the health institutions "inverted triangle" layout and health service "Triangle" distribution. The unreasonable health resource allocation reduces resource utilization efficiency. The phenomenon is a prominent long-standing problem. It is difficult and expensive to see the doctor. At the same time, the rural residents do not get a health care.

Secondly, on the number of the rescue people, the growth rate of the number of urban regions is much higher than in rural areas. This also indicates that the pace of development of urban medical assistance is faster than rural areas. The urban-rural dichotomy gap is gradually widening.

Thirdly, the per capital level of assistance, rural medical assistance levels below the urban. In different forms of medical assistance, the city in serious illness relief, direct aid and the funding levels are higher than rural. The number of China's rural population is much higher than the urban .The proportion of poor is higher in rural than in urban. So, it is more difficult and expensive for urban to see the doctor. Once the urban residents face the serious disease, they also face the plight of the poverty caused by illness. Therefore, the demand of serious medicaid in rural is large in urban.

\subsection{The urban-rural dichotomy of the urban and rural education assistance}

Education assistance refers to the state help schoolage children to complete their education through relief assistance, financing and other ways. Education assistance is a necessary means to achieve educational equity, also is an important way to help poor families. Education assistance is a way to avoid rural poor inter-generation transfer. Meanwhile, it is a way to narrow the education gap between urban and rural. To achieve an important breakthrough in urban and rural development. However, the current education assistance dichotomy problem still exists in rural and urban.

In rural areas, especially in poor marginal rural areas, funding education aid is too small. Because the State Council promulgated the "Two Exemptions and One Subsidy" policy, local rural government financial resources are limited and unable to carry out this policy matching funds this education funding .So local government shifting the burden of financial payments to peasant families in rural. So, some families with many children education become more poor, and some children even give up the opportunity to go to school early .On the country, in the city, it is common to achieve compulsory primary and secondary schools in vast majority and even some high schools have started a pilot implementation of compulsory education.

In addition, many poor urban schoolchildren have been able to receive scholarships and life-time financial subsidies, which greatly improved their living and studying level. In contrast, many rural primary and secondary school students in need of help often get rare education assistance. The children need to go far from home county school. Thus, there is a serious dichotomy educational between urban and rural areas.

\subsection{The urban-rural dichotomy of the urban and rural law assistance}

Firstly, legal aid funding faces a serious shortage and imbalance distribution. Compared with urban residents, due to the limited economic conditions, rural local government could not get enough money to meet the needs of every citizen to apply for legal aid. Legal aid funding shortages still not been effectively resolved.

Secondly, legal aid agencies and teams exist trouble. The law service level and quality to be improved. In countryside, legal institutions in general have not been established. There are few qualified lawyers in rural grassroots legal aid agencies. The people are lack of systematic training. Staff overall service quality needs to be improved. SO, the law aid agencies and staff cannot fully meet the requirements of the legal aid work in countryside.

\subsection{The urban-rural dichotomy of the urban and rural other assistance}

Currently, in the city, disaster assistance has a corresponding set of disaster relief system, which make the basic relief can be done in time. However, in rural areas, especially in some remote villages, the occurrence of natural or man-made disasters, 
because of transportation, communications and other reasons, it is difficult for the rescue team to rescue. In the compensation for the disaster, the compensation standard between urban and rural areas also has a certain gap, which has a very negative impact on disaster relief in urban and rural development.

\subsection{The urban-rural dichotomy of the urban and rural housing assistance}

In city, housing assistance includes low-cost housing, affordable housing and other systems, these assistance protects and improves the housing environment of urban poor residents. For example, the people without room to live have a right to apply housing assistance. In countryside, rural housing finance system lack capital investment, rescue narrow range and even some poor people do not owe the right. Housing assistance includes the poor relocation, housing repairs, even some remote rural areas simply do not enjoy even the housing system.

\section{THE SENSE OF SOCIAL ASSISTANCE URBAN-RURAL OVERALL PLANNING IN CHINA}

Promoting urban and rural social assistance system can ensure the basic livelihood of poor people, also can build a harmonious society as an important part.

\subsection{Contribute to democracy, civil rights and social equity}

Social assistance bases on the human rights principles of the administrative body. Because the right of life is an important human rights.

As a constitutional right, the right of life establishes the civil rights and obligations by the relief and rescue between the state and civil rights. Every citizen equally access this right. So, urban and rural areas must be included within the scope of protection and fair social assistance. Social assistance of urban-rural overall planning affects social equity.

\subsection{Contribute to urban-rural overall planning}

In the overall structure of the social security system, social assistance is the lowest level, acts as an important role. Promote the integration of urban and rural social relief .Set up the fair and effective social assistance that cover all the people and gradually improve the security level of social assistance and fairness. So, all the people share the bonus due to the reform and opening up policy. From" Urban-rural divide to "Urban-rural overall" in social assistance is an effective way to crack the urban-rural dual structure, also is an effective way to promote urban and rural overall development.

\subsection{Contribute to reflect national responsibility}

Protecting the basic life of the poor or the weak is the legal obligation of state and government. Because the social assistance system is actually a national mandatory distribution mechanism. The state as a political entity and the government as the implementing agency of state power. The state should assume responsibility for the citizens of social assistance. The establishment of social assistance urban-rural overall planning is conducive to the country and the government achieve their functions.

\subsection{Contribute to help maintain social stability, and promote social harmony}

Social assistance system as the redistribution of income can effectively reduce the polarization, narrow the gap between the rich and poor, achieve a harmonious society. Because the most urgent people who need help in rural areas, social assistance can help the poor in rural areas and promote the stability city and countryside.

\section{THE SUGGESTION OF CHINA'S SOCIAL ASSISTANCE URBAN- RURAL OVERALL PLANNING IN CHINA}

\subsection{Improve the "Interim Measures for Social Assistance" to speed up the construction of urban and rural social relief system}

February 28, 2014, the State Council held a press conference enacted a provision of the minimum living security aspects "Interim Measures for Social Assistance" implemented since May 1, 2014, Which as a good start to strength legal construction and execute urban and rural social assistance system thoroughly. For minimum subsistence guarantee in countryside, gradually increase the standard rescue. Depending on the price level and the cost of living of different area, the standard rescue exists a certain rang gap. At the same time, China should accelerate rural welfare infrastructure, improve living conditions and welfare of rural environment. In addition, the local government should encourage and guide social forces to participate in the construction of rural minimum subsistence guarantee, gradually establish a diversified investment and various protection mechanism forms. 


\subsection{Establish a unified and coordinated social assistance administration and management system}

The implementation and management of social assistance by using the same set of management systems and information systems. Design a variety of appropriate "seamless channel", which can not affect the right to receive assistance for the poor when they are in different regions, sectors. Further improve the work management system and operation mechanism of "government leaders, civil administration supervisor, department collaboration, community participation". The government should put the integration of urban and rural social relief work into all levels of the important content of the work and performance evaluation of various departments.

\subsection{Broaden the funding sources, increase capital investment and management efforts}

China should effectively increase social assistance funding, broaden sources of funding sources.

Firstly, local governments should actively seek the central, provincial, regional financial bailout money of social assistance.

Secondly, government establish assistance funds growth mechanism adapted to local financial growth.
Thirdly, actively guide social capital investment. The formation of a stable funding system promote the integration of urban and rural social assistance.

\subsection{Fostering non-governmental social welfare organizations}

In emphasizing the country's commitment to social relief duty, we should pay attention to the role of non-governmental organizations. Train and organize the non-governmental social welfare organizations. Develop social volunteers and improve community public service. Promote and carry out social solidarity. All these measures can provide more humane care and social assistance for disadvantaged groups. For example, government can organize the schools, institutions, businesses and even residents donate their goods to the needy people. We can advocate private investors to invest in the rural primary school education.

\section{REFERENCES}

[1] Zhong Renyao 2005.Social Assistance and Social Welfare. Shanghai University of Finance and Economics Press.

[2] Sanxiu Wang Research. May 2010.Chinese social security system. On the rural minimum living security system target transformation.

[3] Yangsi Bin Shandong.January2010. Social Sciences. On the principle of State responsibility in the Social Assistance Act. 